\title{
UM ESTUDO NO SETOR INDUSTRIAL,COMERCIAL E DE PRESTAÇÃO DE SERVIÇOS: o marketing como ferramenta de promoção pessoal
}

\author{
Nairana Radtke Caneppele BUSSLER ${ }^{1}$ \\ Daniel Knebel BAGGIO² \\ Martin LEDERMANN ${ }^{3}$
}

Elias BUSSLER ${ }^{4}$

\begin{abstract}
${ }^{1}$ Mestranda em Desenvolvimento Regional. Unijuí - Universidade Regional do Noroeste do Estado do Rio Grande Do Sul, Brasil.nacaneppele@ hotmail.com

${ }^{2}$ Professor Doutor do Departamento de Ciências Administrativa, Econômicas, Contábeis e da Comunicação Unijuí Universidade Regional do Noroeste do Estado do Rio Grande Do Sul, Brasil. baggiod@unijui.edu.br

${ }^{3}$ Doutorando em Desenvolvimento Regional. Unijuí - Universidade Regional do Noroeste do Estado do Rio Grande Do Sul, Brasil.mcledermann@unijui.edu.br

${ }^{4}$ Pós-Graduado em Finanças e Mercado de Capitais . Unijuí - Universidade Regional do Noroeste do Estado do Rio Grande Do Sul, Brasil. eliaspeli@gmail.com
\end{abstract}

Recebido em: 08/042016 - Aprovado em: 13/10/2017 - Disponibilizado em: 30/12/2017

\begin{abstract}
RESUMO
O presente artigo tem como objetivo identificar se o Marketing Pessoal é fator determinante para o crescimento profissional dos colaboradores pertencentes as empresas dos setores da indústria, comércio e serviços, tanto na opinião dos gestores quanto do quadro funcional. Quanto aos fins, é possível classificar esta pesquisa como descritiva e exploratória e quando aos meios como pesquisa de campo e bibliográfica. Percebeu-se que nestas empresas pertencentes aos diferentes setores da economia os gargalos relacionados as práticas do Marketing Pessoal em comparação com o desejado pelo gestor se encontram em situações diferentes em função da característica de cada empresa ou setor. No setor da indústria, ficou evidenciado que para um colaborador se destacar, esse deve possuir competências para apenas realizar corretamente suas atividades diárias, tornando-se elas repetitivas e programadas. No setor comercial o importante é a aparência do indivíduo e para o setor de serviços, as redes de relacionamento fundamentais para o bom andamento, prospecção, e atingimento das metas.
\end{abstract}

Palavras-chave: Marketing Pessoal. Indústria. Comércio. Serviço. Promoção.

\section{ABSTRACT}

This article aims to identify the Personal Marketing is a determining factor for the professional growth of employees belonging to companies from industry sectors, trade and services, both in the opinion of managers as the staff. As for the purpose, you can sort this research as descriptive and exploratory and when the means as field research and literature. It was noticed that these companies belonging to different sectors of the economy the practices related bottlenecks Personal Marketing compared to the desired by the manager are in different situations depending on the characteristics of each company or industry. In the industry sector, it was evident that for a developer to stand out, this should have skills to only properly carry out their daily activities, they become repetitive and programmed. In the commercial sector the important thing is the appearance of the individual and the service sector, the fundamental social networks for good progress, exploration and achievement of goals.

Keywords:PersonalMarketing .Industry. Trade. Service. Promotion.

\section{INTRODUÇÃO}

Marketing Pessoal é fazer-se notar pelas suas competências e habilidades. É uma ferramenta importante para se chegar ao sucesso pessoal e profissional. Para Kotler
(2003), Marketing Pessoal é uma nova disciplina, que utiliza conceitos e instrumentos do Marketing em benefício da carreira e das vivências pessoais dos 332 
todos os seus atributos, características e complexa estrutura. Portanto, fica claro que Marketing Pessoal não consiste em estar falando o tempo todo sobre si mesmo e suas conquistas, mas sim desenvolver todo o seu eu para que seus atributos e características possam ser valorizados.

O presente estudo apresenta abordagens referentes ao Marketing Pessoal relacionado aos seguintes setores da economia: indústria, comércio e serviços. O estudo foi realizado com os colaboradores e gestores de uma empresa do setor industrial, uma empresa do setor comercial e uma empresa representante do setor de prestação de serviços.

As empresas precisam direcionar a sua imagem juntamente com a dos seus colaboradores, que fazem parte diretamente do Marketing desta. Além disso, precisam ser criativas para crescer e buscar ampliação de mercado com consequência a consolidação da sua marca no mercado consumidor e a concorrência. Assim, surge a necessidade de as empresas darem atenção, foco e aplicabilidade de Marketing direcionado às pessoas que são o mercado consumidor e das pessoas, que são a empresa aos olhos do consumidor, remetendo ao Marketing Pessoal.

Diante do exposto, o presente estudo buscará analisar se o Marketing Pessoal é fator determinante para o crescimento profissional dos funcionários das empresas pertencentes aos setores da indústria, comércio e serviços tanto na visão dos funcionários quanto na visão dos gestores da área de Gestão de Pessoas destas empresas.

\section{REVISÃO DA LITERATURA COMPREENDENDO O MARKETING}

Para saber o que é Marketing Pessoal, faz-se necessário saber antes o que é Marketing e como ele está inserido nas organizações onde os indivíduos são as peças chaves para o desenvolvimento das mesmas.Cobra (1997) afirma que Marketing é uma forma de sentir o mercado e adaptar produtos ou serviços, mas também um compromisso com a busca da melhoria da qualidade de vida das pessoas. Se tudo for feito de forma coerente, o sucesso de venda é a consequência mais lógica e o destino mais previsível. Já Freire e Souza (2001) relatam que Marketing é o processo de planejar e executar a concepção de estabelecimento de preços, promoção e distribuição de ideias, bens e serviços com o objetivo de estabelecer trocas que atendam às metas individuais e organizacionais. Consideram uma atividade sistemática de uma organização humana voltada para a busca de realização com o meio profissional visando ao sucesso de ambas as partes da organização.

Peruzzo (2002) justifica, na mesma linha de raciocínio de Kotler (2000), que Marketing compreende as atividades que uma empresa realiza para se adequar ao ambiente de maneira criativa e rentável atendendo a seu 
público alvo. Nesse sentido, se focar a pessoa em vez da empresa, está também deve se posicionar de modo a se adaptar ao ambiente que o mercado profissional seleciona, uma vez que este pode oferecer oportunidades e ameaças, cabendo ao indivíduo tentar obter ganhos para ele e para os outros, sendo estes pessoas e organizações, justifica o autor. As organizações buscam no mercado informações sobre os desejos e necessidades e recebem deste informações, tornando-se uma indispensável para a outra. Essa busca deve ser constante para que o Marketing possa ser desenvolvido.

\section{O INDIVÍDUO NAS ORGANIZAÇÕES}

Torna-se necessário estudar o papel do indivíduo dentro das organizações e a sua relação com o Marketing visto que ele desempenha o papel fundamental para que as empresas e os produtos e serviços que estas oferecem possam ser bem vistos.As organizações não funcionam sem pessoas, e estas são o seu maior bem. Com isso temos uma relação de troca, pois as organizações dependem das pessoas para atingir seus objetivos e cumprir suas metas assim como as pessoas dependem das organizações para conseguir seus objetivos pessoais.

Para Castells (2003), uma organização é uma colcha de retalhos, de experiências e de interesses em vez de uma carta de direitos e obrigações. Fica claro que o novo comportamento exigido do trabalhador é a sua capacidade de fazer de tudo um pouco, além de ter total domínio de todo o processo e de estar disponível para executá-lo. Um indivíduo volátil, que a cada momento pode modificar-se diante de uma nova necessidade, de interesses e das inúmeras e simultâneas oportunidades, é o motor propulsor do que se pode considerar desenvolvimento e tendência de comportamento nas organizações de hoje.

\section{GESTÃO DE PESSOAS}

A gestão do capital humano nas organizações está diretamente ligada à área de Gestão de Pessoas e a sua habilidade em captar e desenvolver indivíduos nas organizações. Nesse sentido, as empresas que buscam ser competitivas focam o seu cliente interno também. O Marketing, por muito tempo, esteve focado apenas no cliente externo. Hoje, com o cenário de valorização do ser humano, além de conquistar o cliente externo, tem o desafio de engajar os colaboradores para que estes transfiram sua satisfação pessoal ao produto e ao cliente. Assim motivam-se para atingir os seus objetivos e realizar o Marketing Pessoal.

Gil (2008) afirma que a Gestão de Pessoas deve contribuir para que as organizações sejam eficazes por meio das pessoas, pois estas são seu principal motor para impulsionar o desenvolvimento. Assim, buscar a cooperação dos indivíduos que atuam nas organizações é importante tanto para o alcance de seus objetivos individuais 
quanto para o alcance dos objetivos organizacionais.

Chiavenato (2004) considera necessário um processo de reciprocidade entre organização e indivíduo. A Gestão de Pessoas desenvolve seis importantes processos: processo de agregar pessoas; processo de aplicar pessoas;processo de recompensar pessoas;processo de desenvolver pessoas; processo de manter pessoas; e processo de monitorar pessoas. Cada um desses processos tem sua importância para que a organização alcance seus objetivos.

\section{MARKETING PESSOAL}

Os indivíduos estão inseridos em organizações e sistemas. Cada organização possui seu próprio comportamento, e este pode interferir ou não na motivação das pessoas. Estas, se forem bem geridas, apresentarão um bom desempenho e por suas competências poderão desenvolver-se e destacar-se frente aos colegas. Para demonstrar as competências e o desenvolvimento, faz-se necessária a utilização de ferramentas de Marketing Pessoal, que contribuirão para alavancar sua imagem pessoal e profissional.

Marketing Pessoal é uma competência desenvolvida e exposta por meio do comportamento dos indivíduos, dentro e fora das organizações. Envolve relacionamento duradouros. É um processo interpessoal voltado para projetos e planos do futuro. É simples por demonstrar apenas que o indivíduo é, e pode ser complexo por envolver uma rede de relacionamentos através de comportamentos (COLOMBO, 2005).

O conceito central do Marketing é a troca, e o do Marketing Pessoal é a transformação. O Marketing Pessoal analisa a imagem e as características que o aspirante possui e quais o setor deseja e promove as transformações necessárias para aproximar os dois lados e, dessa forma, ocorrer a troca. A transformação da imagem promove mudanças de atitudes, hábitos, comportamento, valores e desejos (KOTLER, 2000).

O Marketing Pessoal é o processo de estar em evidência.Rein (2004) explica que algumas pessoas ganham fama, atingindo o topo do sucesso, enquanto outras permanecem obscuras mesmo tendo capacidade para realizar um excelente trabalho. Visibilidade é o que todo executivo em início de carreira quer, e o que todo profissional incógnito almeja.

Algumas pessoas têm a capacidade de atrair os outros. Elas são espirituosas, animadas e comunicativas. Em qualquer lugar, conseguem se enturmar facilmente, porque sabem como causar uma excelente primeira impressão. São risonhas, confiantes, por isso as pessoas gostam de ficar ao lado delas. Em qualquer relação, seja ela pessoal ou profissional, é necessário reforçar os laços de confiança dia após dia, para ter mais crédito, caso contrário, a pessoa será 
esquecida. Além disso, as pessoas estão na era das redes e dos relacionamentos em que a sua integridade é colocada a toda prova (MATARAZZO, 2002).

\section{METODOLOGIA}

O estudo foi realizado considerando uma amostragem não probabilística por conveniência. Foram aplicados 460 questionários aos funcionários das empresas os quais possuíam 26 questões. Também foram realizadas 3 entrevistas com 7 questões para os gestores da área de Gestão de Pessoas de cada empresa.

Os colaboradores, na empresa representante do setor industrial que responderam ao questionário, foram aqueles que trabalham nas atividades operacionais do processo de produção e totalizaram 202. Na empresa representante do setor comercial, responderam somente os vendedores das lojas e totalizaram 125. Já na empresa representante do setor de serviços, os respondentes foram aqueles que atuam no atendimento direto ao público, tais como caixas, assistentes de atendimento, assistentes de negócios, gerentes de negócios pessoa física e pessoa jurídica, totalizaram 133.

Quanto a coleta de dados, foi necessário realizar pesquisa bibliográfica e pesquisa de campo, aplicando questionários fechados para os colaboradores e entrevista, com os responsáveis pela área de Gestão de Pessoas de cada empresa. A coleta de dados foi realizada entre os meses de julho e agosto de 2014.

\section{RESULTADOS E DISCUSSÃO}

Os colaboradores da empresa representante do setor industrial possuem, em sua maioria, um currículo atualizado, e para pôr em prática o seu Marketing Pessoal utilizam-se de experiência, trabalham sua imagem pessoal e profissional e se relacionam com profissionais de outras áreas.

A empresa representante do setor industrial prega que o Marketing Pessoal é fator crucial para o crescimento dentro da organização, uma vez que as oportunidades de crescimento existem e são disponibilizadas a todo colaborador, porém somente aqueles que se destacam de seus colegas em suas atribuições diárias são promovidos. Não necessariamente um colaborador de maior tempo de casa será promovido, porém aquele assíduo, pontual e que executa com qualidade suas atribuições. Independente do período em que está na empresa, pode estar apto a galgar uma promoção interna. Para a escolha desse colaborador algumas competências são levadas em consideração e têm maior peso, como a busca por qualificação, através de cursos de aperfeiçoamento afirma o gestor da área de Gestão de Pessoas desta empresa.

O Marketing Pessoal dos indivíduos é avaliado por seus comportamentos e ações. Requer relacionamentos interpessoais e visão de futuro. Dessa forma, é possível afirmar que 
todos os indivíduos que estão inseridos em organizações estão sendo avaliados constantemente. Seus gestores, no entanto, possuem sua própria visão, a qual seria ideal que fechasse com o desejo e ambição de seus subordinados.

Os colaboradores da empresa representante do setor comercial, também possuem seus currículos atualizados e possuem a prática de desenvolver habilidade para lidar com pessoas, trabalham suas imagens pessoais e profissionais de modo a atrair clientes e tem como objetivo relacionarse com profissionais de outras áreas para criar redes de relacionamento.

O gestor da área de Gestão de Pessoas da empresa representante do setor comercial afirmou que, o Marketing Pessoal vem ganhando espaço entre os colaboradores, e que aqueles que dominam as ferramentas do Marketing Pessoal se sobressaem nos momentos em que disputam promoções com troca de cargo ou ainda aumento na remuneração. Acredita-se que muitos colaboradores não possuam um completo entendimento do que envolve o Marketing Pessoal. Porém, quando se trata de abertura de vagas internas e promoções, a ferramenta mais utilizada é a competência, ou o conjunto delas.

Quanto às ferramentas do Marketing Pessoal, as principais são as competências, definidas como conhecimento, habilidades e atitude dos colaboradores também a aparência, pois as funcionárias e colaboradores assumem um papel de consultora da cliente em potencial. Para que isso seja possível, a funcionária deve ter assimilado bem seu papel na empresa, para orientar, sugerir, enfim atuar verdadeiramente como consultoras e não como uma simples vendedora, preocupadas apenas com o atingimento de suas metas. Ao encontro dessa situação também se relaciona a questão da aparência, pois, como esses colaboradores tratam diariamente e diretamente com o consumidor final, uma boa apresentação é necessária para um adequado atendimento. Dessa forma, a boa higiene pessoal, o trato com os cabelos, unhas e uniforme são indispensáveis.

No setor de serviços, a principal prática também é possuir um currículo atualizado, desenvolver a habilidade para lidar com pessoas e destacar-se frente a elas, trabalhando a imagem pessoal e profissional para obter resultados que satisfaçam e empresa e o seu próprio ego. Comparecem a festas e confraternizações, bem como relacionam-se também com profissionais de outras áreas seja pensando em seu futuro, ou em negócios dentro da empresa.

O gestor da área de Gestão de Pessoas afirma que em uma ordem de importância, a prática mais importante para desenvolver o Marketing Pessoal é possuir competências para fazer a diferença entre os colegas e assim aparecer.Depois, desenvolver uma 
considerável rede de relacionamentos e para isso é necessário apresentar uma boa aparência. Por últimoéfeita a análise de currículo.
Os resultados indicam que os gestores dessas empresas estão cientes em relação às motivações intrínsecas dos seus colaboradores,

uma vez que houve pouca divergência ou gaps identificados. Isto pode ser uma evidencia de que os gestores estão mais sensibilizados e propensos a compreender seus colaboradores.

Para realizar uma sistematização indústria, comércio e serviços relacionados ao dassemelhanças e diferenças das percepções Marketing Pessoal, apresenta-se o Quadro 1. dos colaboradores e gestores dos setores da

Quadro 1 - Semelhanças e diferenças das percepções dos colaboradores e gestores dos setores da indústria, comércio e serviços relacionados ao Marketing Pessoal

\begin{tabular}{|c|c|c|c|}
\hline \multicolumn{4}{|c|}{ Semelhanças relacionadas ao Marketing Pessoal } \\
\hline & Indústria & Comércio & Serviços \\
\hline $\begin{array}{l}\text { Opinião dos } \\
\text { colaboradores }\end{array}$ & $\begin{array}{l}\text { Trabalham sua } \\
\text { imagem pessoal e } \\
\text { profissional e } \\
\text { acreditam que o } \\
\text { Marketing } \\
\text { Pessoal é fator } \\
\text { determinante para } \\
\text { o crescimento } \\
\text { profissional; }\end{array}$ & $\begin{array}{l}\text { Trabalham sua } \\
\text { imagem pessoal e } \\
\text { profissional e } \\
\text { acreditam que o } \\
\text { Marketing Pessoal } \\
\text { é fator } \\
\text { determinante para } \\
\text { o crescimento } \\
\text { profissional; }\end{array}$ & $\begin{array}{l}\text { Trabalham sua } \\
\text { imagem pessoal e } \\
\text { profissional e } \\
\text { acreditam que o } \\
\text { Marketing Pessoal } \\
\text { é fator } \\
\text { determinante para } \\
\text { o crescimento } \\
\text { profissional; }\end{array}$ \\
\hline $\begin{array}{l}\text { Opinião dos } \\
\text { gestores }\end{array}$ & $\begin{array}{l}\text { Marketing } \\
\text { Pessoal é fator } \\
\text { determinante pois } \\
\text { os colaboradores } \\
\text { que se destacam } \\
\text { serão valorizados; }\end{array}$ & $\begin{array}{l}\text { Marketing Pessoal } \\
\text { é fator } \\
\text { determinante pois } \\
\text { é parte do processo } \\
\text { está relacionado } \\
\text { aos } \\
\text { conhecimentos, } \\
\text { habilidades } \\
\text { atitudes; }\end{array}$ & $\begin{array}{l}\text { Marketing Pessoal } \\
\text { é fator } \\
\text { determinante pois } \\
\text { neste setor é a } \\
\text { primeira } \\
\text { impressão para a } \\
\text { realização } \\
\text { mudanças de } \\
\text { realocações; }\end{array}$ \\
\hline \multicolumn{4}{|c|}{ Diferenças relacionadas ao Marketing Pessoal } \\
\hline & Indústria & Comércio & Serviços \\
\hline $\begin{array}{l}\text { Opinião dos } \\
\text { colaboradores }\end{array}$ & $\begin{array}{l}\text { Competências } \\
\text { estão relacionadas } \\
\text { com experiências; }\end{array}$ & $\begin{array}{l}\text { Competências } \\
\text { estão relacionadas } \\
\text { a habilidades de se } \\
\text { conduzir bons } \\
\text { relacionamentos } \\
\text { com clientes; }\end{array}$ & $\begin{array}{l}\text { Competências } \\
\text { estão relacionadas } \\
\text { a habilidade de } \\
\text { lidar com os } \\
\text { colegas } \\
\text { empresa e com os } \\
\text { clientes; }\end{array}$ \\
\hline Opinião dos & $\begin{array}{l}\text { Competências são } \\
\text { relacionadas ao } \\
\text { ato de fazer }\end{array}$ & $\begin{array}{l}\text { Competências } \\
\text { ligadas } \\
\text { habilidade }\end{array}$ & $\begin{array}{l}\text { Competências } \\
\text { estão } \\
\text { acompanhadas da }\end{array}$ \\
\hline
\end{tabular}




\begin{tabular}{|l|l|l|l|}
\hline gestores & $\begin{array}{l}\text { corretamente as } \\
\text { atividades diárias }\end{array}$ & $\begin{array}{l}\text { conseguir bons } \\
\text { resultados através } \\
\text { seu equilíbrio } \\
\text { emocional a e e e } \\
\text { racional }\end{array}$ & $\begin{array}{l}\text { postura } \\
\text { profissional }\end{array}$ \\
\hline
\end{tabular}

Fonte: Dados da pesquisa, 2014.

Cada setor apresenta uma realidade, exposto a situações diferentes diariamente. Para o setor da indústria, foi possível identificar que a gestora da área de gestão de pessoas acredita que as competências de seus colaboradores estão diretamente ligadas a experiências de fazer diariamente as suas atividadescom excelência, e isso basta. Força de vontade e foco em resultados são importantes para o seu desenvolvimento dentro da empresa. Sendo assim, as competências dos colaboradores da empresa industrial são:

Habilidades nas operações (fazer certo as operações diárias);

Atingir metas de produção de determinada peça;

\section{$\checkmark \quad$ Não errar nenhum processo; \\ $\checkmark \quad$ Cumprir horários; \\ $\checkmark \quad$ Alta assiduidade.}

No setor de comercial, o gestor da área de gestão de pessoas relaciona as competências com a habilidade de se tornar um exemplo de colaborador, tanto no aspecto cognitivo (conhecimento de causa) nas situações racionais, quanto na forma humana de tratar as situações emocionais. Afirma que essas pessoas que diariamente estão em contato com os clientes muitas vezes além de

fisicamente, se cansam emocionalmente. É nesse momento que ele consegue analisar as competências de seus colaboradores, ou seja, aqueles que conseguem se utilizar de conhecimentos, habilidades e atitudes e não se deixam levar pelos problemas do dia-a-dia. Sendo assim, as competências das vendedoras são:

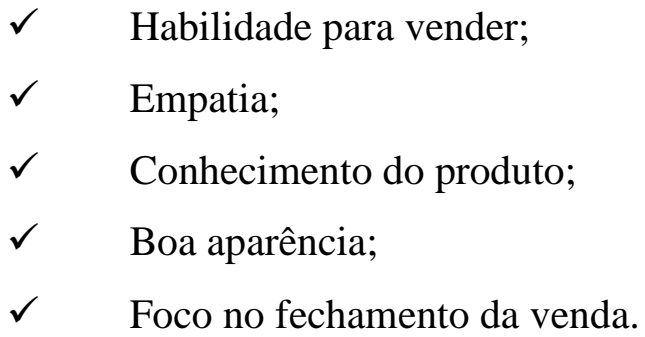

Já o gestor da área de Gestão de Pessoas da empresa representante do setor de serviços, afirma que as competências estão acompanhadas da postura do profissional. Os atributos essenciais para que os colaboradores possam fazer parte do quadro funcional da empresa são:

$\begin{array}{cl}\checkmark & \text { Relacionamento } \\ \checkmark & \text { Capacidade de aprendizado } \\ \checkmark & \text { Comunicação } \\ \checkmark & \text { Comprometimento } \\ \checkmark & \text { Flexibilidade para mudança } \\ \checkmark & \text { Senso crítico. } \\ \text { Os } & \text { colaboradores dessas empresas } \\ \text { da indústria, bem ao encontro do que a }\end{array}$


gestora afirmou, eles acreditam que possuir experiência seria seu diferencial frente aos colegas. Já no setor de comércio, também ao encontro do que o gestor afirmou possuir habilidade para lidar com pessoas foi a resposta escolhida pela maioria dos colaboradores. No setor de serviços, também por se ter o contato direto ao cliente, os colaboradores escolheram a habilidade para lidar com pessoas como seu principal diferencial.

Ao falar em Marketing Pessoal, é preciso relacionar a ideia de aparência pessoal. Quanto a essa ferramenta, a gestora da área de Gestão de Pessoas foi sincera ao dizer que não se preocupa com isso, pois todos utilizam uniformes e estão dentro da fábrica. Já no setor comercial, o gestor afirmou que o mais importante é os colaboradores se tornarem exemplos de bom gosto para que os clientes possam se espelhar positivamente neles. O nível de exigência quanto a aparência sempre será alto. Para o setor de serviços, o gestor afirma que a aparência não só se vestindo bem, mas no sentido de transmitir aos outros uma impressão de como é (por dentro e por fora), da sua personalidade e características pessoais. Ambos possuem diferentes objetivos quando se referem às aparências de seus colaboradores.

Os colaboradores de ambos os setores, afirmam que trabalham suas imagens pessoal e profissional com o objetivo de transferir positivamente suas características e personalidades e que, em suas carreiras aparência é importante.

Em todos os setores os colaboradores responderam que o Marketing Pessoal é fator determinante para o seu crescimento profissional. Para a gestora da área de Gestão de Pessoas do setor da indústria, o Marketing Pessoal é determinante, pois os colaboradores que mais se destacarem sempre são valorizados e indicados para seleções com o objetivo de conseguir outros cargos, o que faz com que consigam desenvolver carreira e crescer por seu próprio desempenho.

O gestor da área de Gestão de Pessoas do setor comercial acredita que é parte do processo, pois o fato de o Marketing Pessoal ser algo de grande valor está relacionado ao conhecimento e às habilidades dentro do ambiente de trabalho. Esses fatores em nada seriam proveitosos se não houvesse a atitude proativa, responsável pelo modo pelo qual o funcionário se faz presente no trabalho. Ser ativo, ter atitudes condizentes e construtivas é um fator fundamental em relação ao Marketing Pessoal, somando forças para um resultado cada vez melhor.

O colaborador será percebido pelo gestor se estiver utilizando correntemente o seu Marketing Pessoal, afirma o gestor da área de Gestão de Pessoas do setor de serviços. Os colaboradores desta empresa estão em constante avaliação do quadro de pessoas, transferências, promoções, trocas de 
função ou desligamentos. $\mathrm{O}$ Marketing Pessoal é a primeira impressão do gestor para pensar nesses movimentos. Tanto o gestor quanto a área de Gestão de Pessoas não devem tomar como base somente sua percepção. Essas decisões devem ser tomadas com base em uma avaliação mais completa. É nessa avaliação que pode ser percebido se o Marketing Pessoal é verdadeiro, condizente com suas competências.

Portanto, através desta pesquisa, foi possível identificar as diferentes percepções tanto dos colaboradores quanto dos gestores em diferentes situações relacionadas ao Marketing Pessoal, considerando que cada empresa está inserida em diferentes contextos. Algumas já foram elencadas quando se falou sobre os gaps, mas tornaram-se importantes para a realização das conclusões desse trabalho de conclusão de curso, pois contempla um dos objetivos propostos.

\section{CONSIDERAÇÕES FINAIS}

Percebeu-se que nestas empresas pertencentes aos diferentes setores da economia os gargalos relacionados as práticas do Marketing Pessoal em comparação com o desejado pelo gestor se encontram em situações diferentes. No setor da indústria, ficou evidenciado que para que um colaborador possa se destacar, esse deve possuir competências para apenas realizar corretamente suas atividades diárias. No setor comercial o importante é a aparência do indivíduo e para o setor de serviços, as redes de relacionamento fundamentais para o bom andamento, prospecção, e atingimento das metas. Já no setor de serviços, a prática mais importante para a empresa é as redes de relacionamento e para os colaboradores são suas competências.

Ao finalizar este estudo conclui-se que estas empresas possuem um grande potencial o conhecimento necessário para desenvolver carreiras e indivíduos promissores. Para tanto é necessário propor situações onde esses colaboradores possam mostrar seus lados intraempreendedores para que possam se destacar diante de seus colegas e com isso realizar o Marketing Pessoal que fortalecerá suas marcas pessoais na empresa.

O Marketing Pessoal procura personalizar ações com relação ao trabalho do colaborador e logo com o cliente ou usuário, ouvindo-o e orientando-o. Esse relacionamento deverá gerar parcerias na relação de trocas buscando transformar usuários em consumidores fiéis e leais, também mostrar a importância do colaborador para a empresa que será a peça principal nesse movimento.

Portanto o presente estudo contribuiu na área de Marketing, mais especificamente na área de Marketing Pessoal e na maneira dos gestores da área de Gestão de Pessoal analisam as atitudes desses colaboradores. Entende-se que esses gestores a partir do estudo possuem a visão de como os seus 
colaboradores realizam o seu Marketing

Pessoal, bem como, esses colaboradores também sabem de que forma poderão utilizar suas competências.

Quanto as limitações do estudo, seria possível ter realizado mais entrevistas e questionários bem como um comparativo com outras empresas do mesmo setor para verificar se realmente as práticas descritas podem ser utilizadas para esses setores da economia. Estas limitações podem dar início a estudos futuros nesta ideia.

\section{REFERÊNCIAS BIBLIOGRÁFICAS}

CASTELLS, M.A sociedade em rede. $7^{\circ}$ edição. São Paulo: Paz e Terra, 2003.

CHIAVENATO, I. Gestão de pessoas: o novo papel dos recursos humanos nas organizações. $4^{\circ}$ edição. Rio de Janeiro: Elsevier, 2004.

COBRA, M.Marketing básico: uma abordagem brasileira. $4^{\circ}$ edição. São Paulo: Atlas, 1997.

COLOMBO, S. S.Marketing pessoal. $1^{\circ}$ edição. Porto Alegre: Artmed/Bookmann, 2005.

FREIRE, P; SOUZA, J.Marketing, gestão e carreira. Reflexões sobre temas empresariais. $2^{\circ}$ edição. Salvador: Ed. Faculdade de Tecnologia Empresarial, 2001.

GIL, A. C.Gestão de pessoas: enfoque nos papéis profissionais. $3^{\circ}$ edição. São Paulo: Atlas, 2008.
Para concluir é importante afirmar que o Marketing Pessoal é fator determinante para o crescimento dos colaboradores pertencentes as empresas dos setores da indústria, comércio e serviços, tanto na opinião dos gestores quanto do quadro funcional em todas as empresas e não é uma decisão de projeção de imagem que se toma num instante específico da carreira do profissional, mas sim, um conjunto de ações que devem ser incorporadas ao dia-a-dia de todo profissional, acrescentando esse procedimento às suas qualificações.

KOTLER, P.Administração de Marketing. Tradução Bazán Tecnologia e Lingüística. 10 edição. São Paulo: Prentice Hall, 2000.

.Princípios de marketing. $9^{\circ}$ edição. Rio de Janeiro: Prentice-Hall do Brasil. 2003.

MATARAZZO, C.Etiqueta sem frescura, etiqueta sem frescura. $1^{\circ}$ edição. São Paulo: Melhoramentos, 2002.

PERUZZO, M. Marketing pessoal. [Online]. Disponível em: http://www.ebah.com.br/content/ABAAAfpp oAC/marketing-pessoal. [11 maio 2014], 2002.

REIN, I. Marketing de alta visibilidade. [Online] Disponível em:http://www.guiarh.com.br/prh4.html. [10 abr. 2014], 2004. 